\title{
Patients hospitalized with COVID-19 have low levels of 25-hydroxyvitamin D
}

\author{
Nicholas Hutchings $\mathbb{D}^{1,2} \cdot$ Varta Babalyan ${ }^{2}$ - Sisak Baghdasaryan ${ }^{2} \cdot$ Mushegh Qefoyan $^{2} \cdot$ Narina Sargsyants $^{3}$. \\ Elena Aghajanova ${ }^{4}$. Anna Martirosyan ${ }^{5} \cdot$ Ruzanna Harutyunyan $^{5} \cdot$ Olga Lesnyak $^{6}$ - Anna Maria Formenti ${ }^{7}$. \\ Andrea Giustina $^{7} \cdot$ John P. Bilezikian ${ }^{2,8}$
}

Received: 24 November 2020 / Accepted: 17 December 2020 / Published online: 16 January 2021

(c) The Author(s), under exclusive licence to Springer Science+Business Media, LLC part of Springer Nature 2021

The coronavirus (SARS-CoV-2) causes COVID-19. The disease has already afflicted over 54 million persons worldwide and has caused over 1.3 million deaths [1]. While most patients recovery uneventfully, some develop an acute pulmonary syndrome that requires hospitalization for supportive care [2]. Risk factors for symptomatic manifestations include male sex, diabetes mellitus, obesity, and hypertension [3, 4]. Another recently recognized potential risk factor is vitamin $D$ deficiency. Vitamin $D$ is an important modulator of innate and acquired immunity $[5,6]$. Low levels are associated with bacterial and viral infections [7]. In addition, in countries with lower mean levels of 25-hydroxyvitamin D, mortality from COVID-19 is higher [8]. Preliminary studies suggest that vitamin D supplementation may improve outcomes [9]. While much of the data implicating vitamin D and COVID-19 has been indirect, recent reports have shown markedly reduced levels of 25-hydroxyvitamin D among those hospitalized with COVID-19 [10, 11]. These observations are consistent with

Nicholas Hutchings

nicholas.hutchings@uci.edu

1 School of Medicine, University of California, Irvine, CA, USA

2 Osteoporosis Center of Armenia, Yerevan, Armenia

3 Ministry of Health, Yerevan, Armenia

4 Muratsan University Hospital, Yerevan, Armenia

5 Saint Gregory the Illuminator Medical Center, Yerevan, Armenia

6 North West State Medical University named after I.I. Mechnikov, Saint Petersburg, Russia

7 Institute of Endocrine and Metabolic Sciences, San Raffaele, Vita-Salute University and IRCCS Hospital, Milano, Italy

8 Endocrinology Division, Department of Medicine, New YorkPresbyterian Hospital / Columbia University Irving Medical Center, New York, NY, USA a plausible pathophysiological role of vitamin $D$ in the disease process [6].

With an ethnically and culturally homogeneous population of approximately 3 million [12], Armenia has seen 116,000 cases and 1700 deaths as of November 2020 [13]. At the Saint Gregory the Illuminator Medical Center (SGIMC) in Yerevan, a designated COVID-19 treatment hospital, we measured levels of 25-hydroxyvitamin D. We compared these levels with values that we have recently characterized in the free-living, healthy population of Armenia [14].

\section{Methods}

Blood samples for measurement of 25-hydroxyvitamin D (ElectroChemiLuminescence immunoassay: Cobas e 411 autoanalyzer- Roche; Basel, Switzerland) were obtained from 330 consecutive hospitalized patients. We also recorded age, gender, height, weight, occupation, chronic conditions, prior tuberculosis infection, smoking status, use of supplemental oxygen, intubation status, duration of hospitalization until discharge, or death.

\section{Results}

Samples were collected over 5 weeks in summer, 2020. The most common comorbidities were hypertension, diabetes, smoking, and prior lung disease. Mean duration of hospitalization was $11 \pm 7.4$ days. A majority (52\%) required supplemental oxygen but only $4.5 \%$ were intubated. There were 24 deaths (7.3\%). Mean 25-hydroxyvitamin D level was $13.4 \pm$ $7.7 \mathrm{ng} / \mathrm{mL}$, with $45 \%$ of patients under $12 \mathrm{ng} / \mathrm{mL}$. See Table 1 .

Positive relationships were noted between age and the duration of hospitalization, age and days on supplemental oxygen, BMI and days hospitalized, BMI with days on 
Table 1 Demographic and clinical characteristics, and laboratory findings of patients hospitalized with COVID-19

\begin{tabular}{ll}
\hline Patient count & 330 \\
Gender & $39 \%$ male \\
Mean age & $57 \pm 17$ years \\
Mean BMI & $28.2 \pm 5.8 \mathrm{~kg} / \mathrm{m}^{2}$ \\
Comorbidities & Hypertension $(27.5 \%)$ \\
& Diabetes $(16 \%)$ \\
& Smoking $(11.5 \%)$ \\
Hospital stay & Lung disease $(7.3 \%)$ \\
Use of supplemental oxygen & $11 \pm 7.4$ days \\
Intubation & 171 patients $(52 \%)$ \\
Death & 15 patients $(4.5 \%)$ \\
Mean 25-hydroxyvitamin D & $24(7.3 \%)$ \\
25-hydroxyvitamin D $<12 \mathrm{ng} / \mathrm{mL}$ & $13.4 \pm 7.7 \mathrm{ng} / \mathrm{mL}$ \\
\hline
\end{tabular}

supplemental oxygen, and number of comorbidities with days on supplemental oxygen. In addition, multivariate logistic regression identified age and duration of hospitalization and significant variables for death. There was no relationship between any of the demographic variables and intubation.

We found no significant relationship between 25hydroxyvitamin D and BMI, duration of stay, oxygen requirements, or death. The mean level of $13.4 \pm 7.7 \mathrm{ng} / \mathrm{mL}$ was markedly lower than the mean 25 -hydroxyvitamin $\mathrm{D}$ level among women in Armenia of $19.8 \pm 7.6 \mathrm{ng} / \mathrm{m}(p<0.0001)$. Mean vitamin D of those patients who passed away was mildly lower than that of those who survived, however the difference was not significant $(11.69 \mathrm{ng} / \mathrm{mL}$ vs $13.51 \mathrm{ng} / \mathrm{mL}, p=0.27)$. A greater proportion of hospitalized patients had levels below $12 \mathrm{ng} / \mathrm{mL}$ in comparison to the national average, but in comparing those with vitamin $\mathrm{D}$ levels below $12 \mathrm{ng} / \mathrm{mL}$ to those with vitamin D levels above $12 \mathrm{ng} / \mathrm{mL}$, we found no difference in terms of mean age, BMI, duration of hospitalization, or days requiring supplemental oxygen.

\section{Discussion}

The results of this report support a potential role for vitamin D as a risk factor for COVID-19, as suggested recently in studies from Italy and Spain $[11,15]$. It also adds clinical strength to much basic information implicating vitamin $\mathrm{D}$ in the native and acquired immune response.

An additional strength of this study is the newly acquired reference data on healthy subjects' 25-hydroxyvitamin levels in Armenia with which these significantly lower levels could be compared [14]. What is also noteworthy is the very low levels of 25-hydroxyvitamin D, below $12 \mathrm{ng} /$ $\mathrm{mL}$, a threshold value acknowledged by all authoritative bodies to be associated with frank, unequivocal vitamin D deficiency. Almost half the infected population was below this value, a markedly greater percentage than in our reference population in which such low levels were seen in only $13 \%$. Such very low levels could have devastating effects upon the host's ability to contain the acquired immune response as well as bolster its cellular defense mechanisms.

Additional strengths of this study include the size of the patient cohort and the homogeneity of the cohort which reduces the influence of cultural, ethic, or lifestyle on disease severity. Limitations include the lack of a pre-SARSCoV-2 infection 25-hydroxyvitamin D level in the individual patients. In addition, we do not know the extent to which the acute illness itself might have influenced the level of vitamin D or vitamin D binding protein, the latter of which we did not measure.

It is important to conduct prospective studies to determine if intervention with vitamin $\mathrm{D}$ can be protective against COVID-19 as well as whether intervention with vitamin $\mathrm{D}$ can mitigate its severity.

Acknowledgements We acknowledge the nursing staff and administration of the Saint Gregory the Illuminator Medical Center for their assistance in collecting the data, John Williams for statistical support, and the Ministry of Health of the Republic of Armenia for its interest and logistical support.

Funding This project was supported by Abiogen and Glucocorticoid Induced Osteoporosis Skeletal Endocrinology Group (GIOSEG). Neither source of support had any role in the design, executive, analysis, or preparation of the manuscript.

\section{Compliance with ethical standards}

Conflict of interest The authors declare that they have no conflict of interest.

Ethical approval All procedures performed in studies involving human participants were in accordance with the ethical standards of the institutional and/or national research committee and with the 1964 Helsinki declaration and its later amendments or comparable ethical standards. This study was approved by the Institutional Review Board of Columbia University Irving Medical Center, and the Ethics Committee of the Yerevan State Medical University.

Informed consent Both review boards waived informed consent as a requirement because the study entailed analysis of previously collected and de-identified data.

Publisher's note Springer Nature remains neutral with regard to jurisdictional claims in published maps and institutional affiliations.

\section{References}

1. Worldometer. COVID-19 Coronavirus Pandemic. Accessed 07 Nov 2020 
2. CDC. Interim Clinical Guidance for Management of Patients with Confirmed Coronavirus Disease (COVID-19). Accessed 07 May 2020

3. J. Yang, Y. Zheng, X. Gou, et al. Prevalence of comorbidities and its effects in coronavirus disease 2019 patients: a systematic review and meta-analysis. Int J. Infect. Dis. 94, 91-95 (2020)

4. S.Richardson, J.Hirsch, M.Narasimhan, et al. Presenting characteristics, comorbidities, and outcomes among 5700 patients hospitalized with COVID-19 in the New York city area. JAMA 323(20), 2052-2059 (2020)

5. M. Hewison, Vitamin D and the intracrinology of innate immunity. Mol. Cell. Endocrinol. 321, 103-111 (2010)

6. J.P. Bilezikian, D. Bikle, M. Hewison, et al. Mechanisms in endocrinology: Vitamin D and COVID-19. Eur. J. Endocrinol. 183, R133-R147 (2020)

7. A. Martineau, D. Jolliffe, R. Hooper, et al. Vitamin D supplementation to prevent acute respiratory tract infections: systematic review and meta-analysis of individual participant data. BMJ 356, i6583 (2017)

8. P. Ilie, S. Stefanescu, L. Smith, The role of Vitamin D in the prevention of Coronavirus Disease 2019 infection and mortality. Res. Square. Accessed 07 May 2020

9. M. Entrenas Castillo, L.M. Entrenas Costa, Vaquero, J.M. Barrios, et al. Effect of calcifediol treatment and best available therapy versus best available therapy on intensive care unit admission and mortality among patients hospitalized for COVID-19: a pilot randomized clinical study. J. Steroid Biochem. Mol. Biol. 203, 105751 (2020)

10. L. Gennari, I. Campi, D. Merlotti, et al. Vitamin D Deficiency Is Independently Associated with COVID-19 Severity and Mortality. Oral Presentation: American Society for Bone and Mineral Research Annual Meeting, 11 Sep 2020 (virtual)

11. J. Hernández, D. Nan, M. Fernandez-Ayala, et al. Vitamin D status in hospitalized patients with SARS-CoV-2 infection. J. Clin. Endocrinol. Metab. 2020, dgaa733. https://doi.org/10.1210/clinem/dgaa733, https://academic.oup.com/jcem/advance-article/doi/10.1210/clinem/ dgaa733/5934827. Accessed 06 Jan 2021

12. Central Intelligence Agency. CIA Factbook: Armenia. Accessed 07 May 2020

13. Ministry of Health of the Republic of Armenia. Current coronavirus situation in the country. https://www.moh.am/\#1/3336 Accessed 09 Nov 2020 [Armenian]

14. N. Hutchings, V. Babalyan, A. Heijboer, et al. Vitamin D Insufficiency is widespread in Armenia. Poster Presentation. American Society for Bone and Mineral Research Annual Meeting, 11 Sep 2020 (virtual)

15. L. Gennari, I. Campi, D. Merlotti, et al. Vitamin D deficiency is independently associated with COVID-19 severity and mortality. Oral Presentation: American Society for Bone and Mineral Research Annual Meeting, 11 Sep 2020 (virtual) 